Available online at GSC Online Press Directory

GSC Biological and Pharmaceutical Sciences

e-ISSN: 2581-3250, CODEN (USA): GBPSC2

Journal homepage: https://www.gsconlinepress.com/journals/gscbps

(RESEARCH ARTICLE)

\title{
Investigation of the occurrence of entomopathogenic fungi in soils and on insects from Corentyne Berbice, Guyana
}

\author{
Ferial Pestano ${ }^{1}$, Subramanian Gomathinayagam ${ }^{2,{ }^{*}}$, Abdullah Ansari ${ }^{3}$ and Phillip Da Silva ${ }^{1}$ \\ ${ }^{1}$ Division of Natural Sciences, University of Guyana, Berbice Campus, Tain, Guyana. \\ 2 Faculty of Agriculture, University of Guyana, Berbice Campus, Tain, Guyana \\ ${ }^{3}$ Faculty of Natural Sciences, University of Guyana, Turkeyen Campus, Georgetown, Guyana. \\ ${ }^{4}$ Division of Natural Sciences, University of Guyana, Berbice Campus, Tain, Guyana.
}

Publication history: Received on 17 July 2019; revised on 28 August 2019; accepted on 04 September 2019

Article DOI: https://doi.org/10.30574/gscbps.2019.8.3.0134

\begin{abstract}
Entomopathogenic fungi is a component of pest management systems in some countries, and have great potential as a biological control agent against insects. The purpose of this study was to investigate the occurrence of entomopathogenic fungi in soils and on insects from Corentyne Berbice, Guyana South America. A total of 190 insects were collected; which belonged to 14 insect families. They are Aleyrodidae, Coreidae, Acrididae, Blattidae, Drepanidae, Libellulidae, Lycaenidae, Pieridae, Vespidae, Apidae, Formicidae, Culicidae, Scarabaeidae and Muscidae. Acrididae was found to be the most dominant insect family. However, insect-associated fungi were defined to include known entomopathogenic fungi, secondary colonizers and non-pathogenic colonizers. Entomopathogenic fungi found from the insects were Beauveria bassiana, Lecanicillium, Fusarium, and Paecilomyces, comprising of 5.62, 1.41, 3.28 and 0.94 isolation percentage respectively. Among the secondary colonizers, Alternaria, Curvularia, Penicillium, and Cladosporium were found, comprising 4.22, 14.75, 5.62, and 5.15 isolation percentage respectively. Non-pathogenic colonizers had high occurrences; among them was Aspergillus niger, Aspergillus flavus, Aspergillus versicolor, Aspergillus clavatus, Phytophthora, Pyricularia, Mucor, Bipolaris, Trichophyton, Trichoderma, and Rhizopus, comprising $22.72,14.75,1.64,1.41,1.41,3.51,7.26,0.47,0.23,4.22$ and 1.41 isolation percentage respectively. Moreover, $B$. bassiana was the only entomopathogenic isolate from the soil samples, comprising of 11.25 isolation percentage. Other soil colonizers present were A. niger, A. flavus, Penicillium, A. clavatus, Mucor, and Rhizopus, comprising of 11.25, $16.25,6.25,6.25,21.25$, and 27.50 isolation percentage respectively. These findings highlight that entomopathogenic fungi are present in the bio-systems chosen and further investigations are necessary to establish an effective biocontrol strategy.
\end{abstract}

Keywords: Entomopathogenic fungi; Pest management; Soil colonizers; Soil, fungi; Bacteria

\section{Introduction}

Insects are known to include more than half of all living things, and comprises over a million described species [1]. Species considered pests includes those that destroy agricultural goods (for example, locusts), those that are parasitic (for example, lice), those that are transmitters of diseases (for example, mosquitoes), those that cause damages to forest (for example, Bark beetles) and those that cause damages to structures (for example, termites). They are also found living in virtually all environments, with a few species residing in oceans [2] [1].

Presently, there are many ways to control insects. Pest control includes a wide range of insecticides and also make use of biological pest control also known as biocontrol [2]. However, there are multiple concerns regarding the negative

\footnotetext{
${ }^{*}$ Corresponding author

E-mail address: directorugbc@uog.edu.gy
} 
effects pesticides pose on the environment; since it defeats the purpose of the green revolution, by affecting the health of other organisms when applied [2]. Alternative biocontrol method includes the use of insect parasitoids, pathogens and predators. Of these biocontrol methods, pathogens specifically entomopathogenic fungi is the utmost promising [4].

According to [5], distribution of entomopathogenic fungal species is different. They are known to be found in a wide variety of terrestrial biomes worldwide. Moreover, Beauveria bassiana is an example of a species that has been found throughout the world, in places like Canada and many tropical rainforests. In addition, species such as Tolypocladium cylindrosporum, Beauveria bassiana and Metarhizium anisopliae were recorded in Norway, while Beauveria bassiana, Metarhizium anisopliae and Isaria farinosa (also known as Paecilomyces farinosus) were recorded in Finland. Baseline studies are limited on these pathogens in Guyana; therefore, the present study aims to investigate the occurrence of entomopathogenic fungi in soils and on insects from Corentyne Berbice, Guyana.

Insect's success in being pest to many crops can be attributed by copious factors. Firstly, their ability to survive on any substances that have nutritive value, secondly, their small size, which is a crucial attribute allowing them to occupy very diverse niches, and lastly, their wings which assist in finding new habitats during times of stress [6].

Enlightened that [7], most major pest of crops, found in Guyana, belongs to three insect orders. These are Lepidoptera (for example, Mocis latipes), Hemiptera (for example, Oebalus poecilus), and Coleoptera (for example, Sitophilus oryzae); they attack crops such as sugarcane and rice. Additionally, infestations caused by insects, are creating major problems in Guyana, since it causes loses to crops and revenue. Farmers residing in Pomeroon-Supenaam, have recently been complaining about problems experienced due to paddy bug (Oebalus poecilus) invasion [8]. Moreover, the Agriculture sector contributed about 20.6 percent to Gross Domestic Product (GDP), during the year 2016. Infestations caused by insects can affect Guyana's economic status, by damaging crops and the quantity in which they are produced [9].

The use of entomopathogenic fungi as biocontrol agents against insect pest can be of great benefit, since these fungi have a narrow host range, target a specific pest population while preserving natural predators and beneficial insects, and are also highly virulent [10].

Entomopathogenic fungi occur naturally in insect hosts as infections. They are fungi which encourage disease symptoms in insects and range from quick killers to absolute parasites. These fungi vary in their mode of action and virulence; with the success of their penetration depending on their ability to adhere and penetrate the integuments of the host. They release a variety of extracellular enzymes during the degradation of the insect's integument [11]. These fungi are important and widespread in most terrestrial ecosystems, however, the prevalence of individual species are different and some can be found worldwide [5]. Entomopathogenic fungi have scopes in Guyana, since it can address agricultural issues. These fungi can be of great benefits as biocontrol, a form of better management practice.

\section{Material and methods}

\subsection{Site of work}

This project was carried out at three different bio-systems in Corentyne Berbice, Guyana. These bio-systems are a rice field, a sugarcane field and the University of Guyana John's Science Center.

\subsection{Materials}

Sweeping net, deep net, beating tray, areal net, light source, white cloth, bait, paper bags, insect cage, lactophenol cotton blue, agar, petri dish and sodium hypochlorite.

\subsection{Sampling method}

Stratified random sampling was used to collect insects, and soil samples. Using this method, the bio-systems were divided into four non-overlapping subpopulations or strata. Samples were removed from each stratum once a week [12]. However, a sampling effort of one hour was given to each stratum for the collection of insects.

Live insects [4] collection to capture live insects, traps and tools were used. Some tools that was used are: sweeping net, deep net, beating tray and areal net. Some traps that was used are: pitfall trap, light trap, and bait trap and insects was stored in cages and fed. 
Ferial et al. / GSC Biological and Pharmaceutical Sciences 2019, 08(03), 001-009

Soil sample [13] were collected from 3 points in each stratum randomly. The samples were mixed in order to be homogeneous. Samples was collected $0-20 \mathrm{~cm}$ in depth, in order to remove the top layer.

\subsection{Identification of insects}

After storage the insects was identified up to the family, with the use of dichotomous keys [14]. Isolation of Entomopathogenic fungi [4] method were used. Field collected entomopathogenic fungi, a small piece of the material was placed in a small dissecting dish. Tiny pieces of both mycelium and spores were tease off using a sterile needle. A small pool of lactophenol cotton blue was placed on a clean, grease-free microscope slide; and a clean cover slip was lowered over. It was then observed under the microscope.

Newly dead insects with no external growth. These insects were incubated for several days at high humidity, and sporulation was observed. The spores were then mount on a slide in water and was observed using a microscope. Insects which have been dead for a long time. These insects were surface sterilized using sodium hypochlorite for several minutes; then rinsed in three (3) changes of sterile distilled water. The internal tissues were then dissected and spores was streaked onto potato dextrose agar. The culture was incubated at $20-28{ }^{\circ} \mathrm{C}$ and was examined daily. Live insects were removed from the cages, swabbed and streak onto the potato dextrose agar.

Soil samples collection were used [13], 2003 methods, A 2mm sieve was used to sieve the soil samples and they were stored at 4 degrees in the dark before use. Before using, the soil was spread and aggregates were broken in order to keep it open; to ensure it equilibrate with the laboratory. Using a $1 \mathrm{~mm}$ sieve each sample was then sieved and placed in a sterile test tube. Distillated water was then added to the test tube and mixed in order to form a solution. Three (3) to four (4) drops of the solution was then added to potato dextrose agar; replicates were made for each strata within each bio-system. The culture was incubated at $20-28{ }^{\circ} \mathrm{C}$ and was examined daily. The spores were then mount on a slide in water and was observed using a microscope.

\section{Results and discussion}

The aim of this research was to investigate the presence of entomopathogenic fungi in soils and on insects from three different bio-systems in Corentyne Berbice.

Table 1 Fungal isolates obtained from the insects

\begin{tabular}{ll}
\hline Categories & Fungal isolates \\
\hline Entomopathogenic fungi & 1. Beauveria bassiana \\
& 2. Lecanicillium \\
& 3. Fusarium \\
& 4. Paecilomyces \\
\hline Secondary colonizers & 1. Alternaria \\
2. Curvularia \\
3. Penicillium \\
4. Cladosporium \\
1. Aspergillus niger \\
2. Aspergillus flavus \\
3. Aspergillus versicolor \\
4. Aspergillus clavatus \\
5. Phytophthora \\
6. Pyricularia \\
7. Mucor \\
8. Bipolaris \\
9. Trichophyton \\
10. Trichoderma \\
11. Rhizopus
\end{tabular}

From the table 1 it can be seen that 19 different fungi were isolated from the insects. These species were categorized as entomopathogenic if they are parasitic to insects, secondary colonizers if they can parasitize an insect once the immune system is compromised, and non-pathogenic colonizers if they are unable to parasitize an insect. The entomopathogenic species includes Beauveria bassiana, Lecanicillium, Fusarium and Paecilomyces. Secondary 
colonizer includes Alternaria, Curvularia, Penicillium and Cladosporium. Finally, non-pathogenic colonizer includes Aspergillus niger, Aspergillus flavus, Aspergillus versicolor, Aspergillus clavatus, Phytophthora, Pyricularia, Mucor, Bipolaris, Trichophyton, Trichoderma and Rhizopus.

Table 2 Fungal isolates obtained from the soil samples

\begin{tabular}{ll}
\hline Categories & Fungal isolates \\
\hline Entomopathogenic fungi & 1. Beauveria bassiana \\
\hline Other colonizers & 1. Aspergillus niger \\
& 2. Aspergillus flavus \\
& 3. Penicillium \\
& 4. Mucor \\
& 5. Rhizopus \\
\hline
\end{tabular}

From the table it can be seen that six different fungi were isolated from the soil samples. The species were also categorized based on their ability to infect insects. Beauveria bassiana was the only species that was entomopathogenic. There were five colonizers that are not considered entomopathogenic; among these are $A$. niger, $A$. flavus, Penicillium, Mucor and Rhizopus etc.

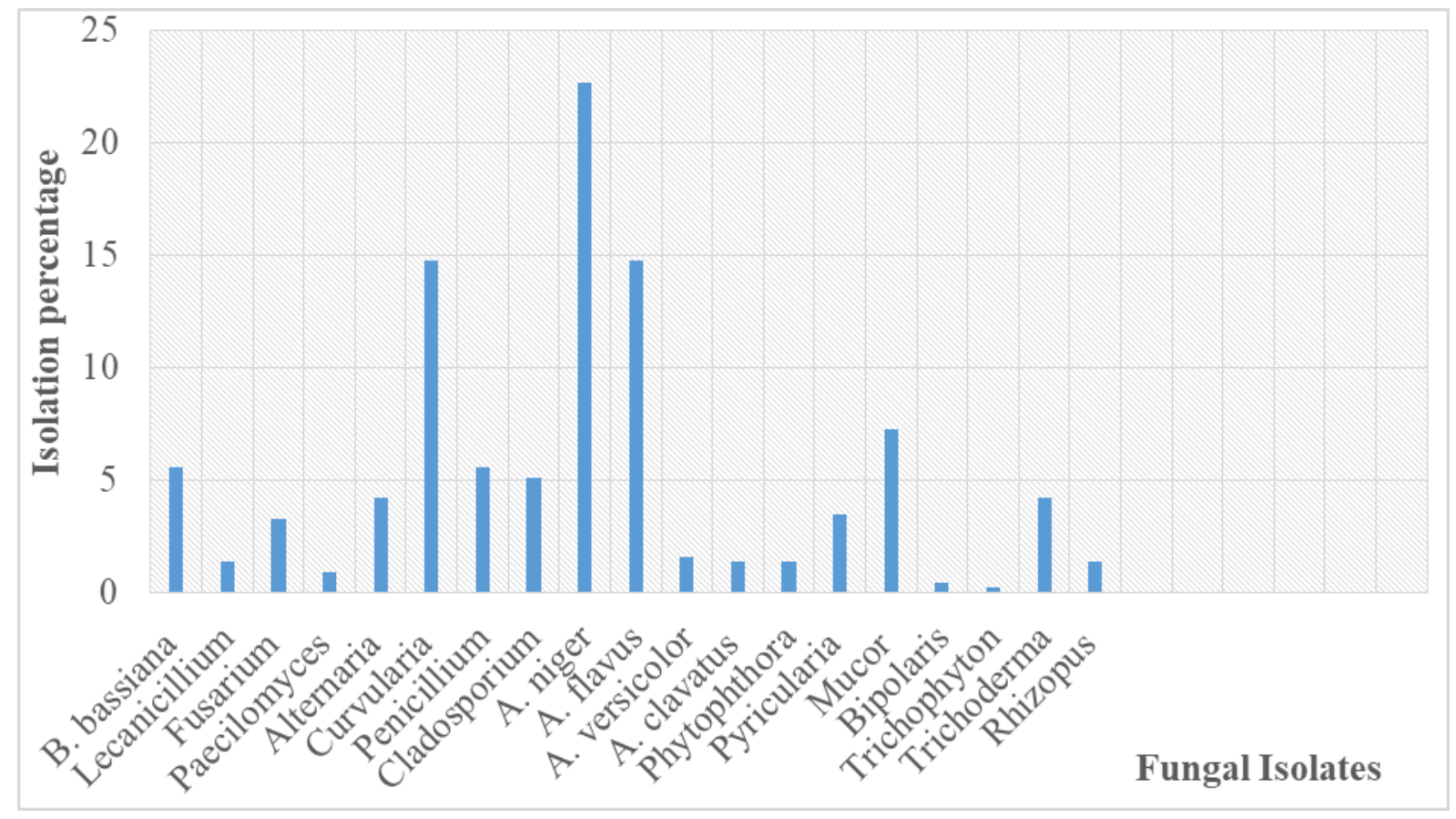

Figure 1 The isolation percentage for the fungal isolates obtained from the insects

From the above figure 1 it can be seen that Aspergillus niger had the greatest isolation percentage followed by Aspergillus flavus, Curvularia, Mucor, Beauveria bassiana, Penicillium, Cladosporium, Trichoderma, Alternaria, Pyricularia, Fusarium, Aspergillus versicolor, Lecanicillium, Phytophthora and Rhizopus. Paecilomyces, Bipolaris and Trichophyton had the least isolation percentage.

Aspergillus niger is expected to be the most abundant isolate; since, it is widely distributed in the environment. This species can be found in the soil, on plants and decaying vegetables, in dust, on stored food, fruits, vegetable, feed products and in the air [15]. Additionally, Beauveria bassiana had the greatest isolation percentage among the other entomopathogenic fungi. This is also expected since they are known to be natural enemies to many insect species and has a cosmopolitan distribution [16]. 


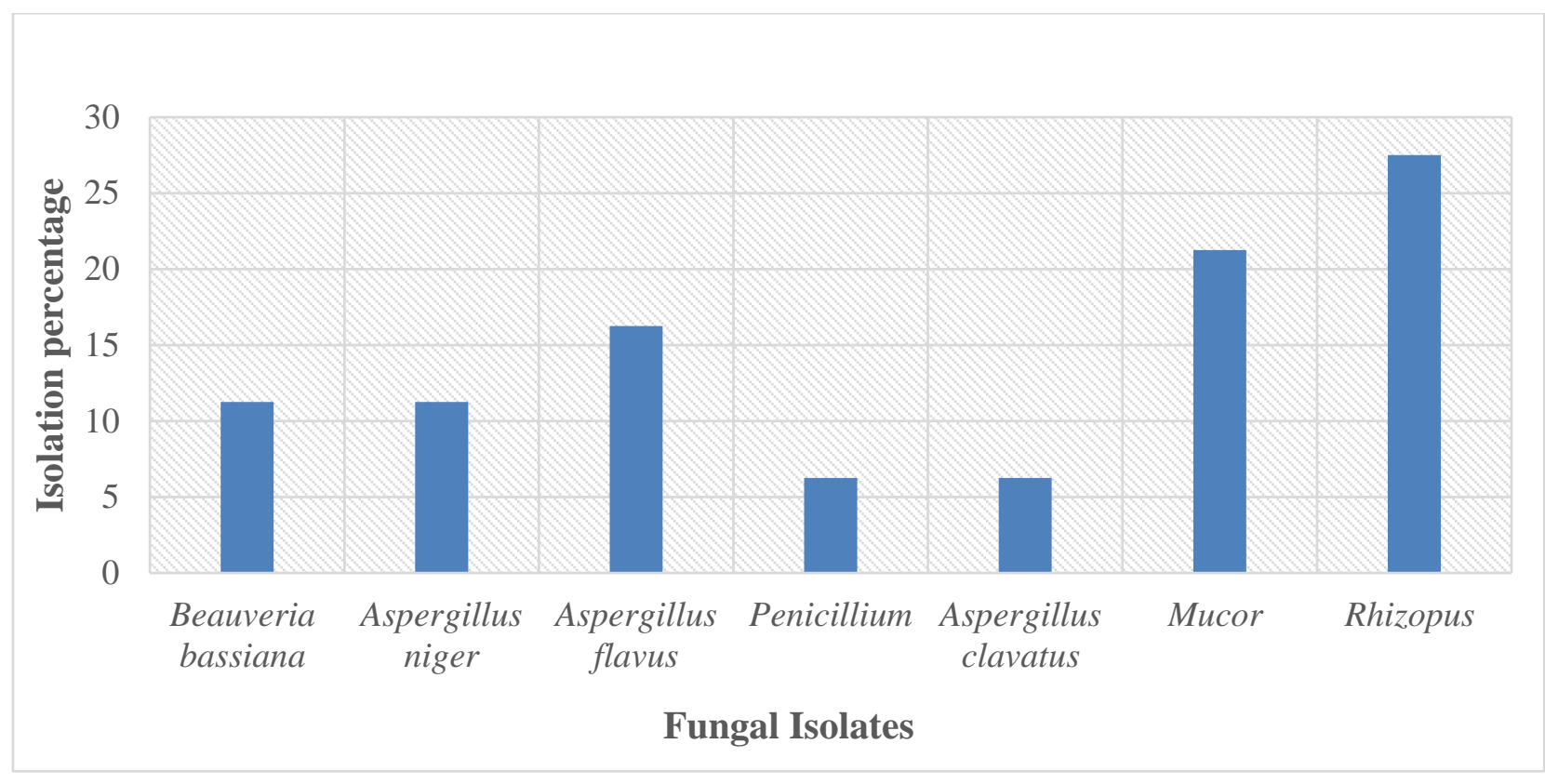

Figure 2 The isolation percentage for the fungal isolates obtained from the soil samples

Figure 2 above shows that Rhizopus was the fungus with the greatest isolation percentage, followed by Mucor, Aspergillus flavus, Beauveria bassiana, Aspergillus niger, Penicillium and lastly, Aspergillus clavatus. Additionally, soil is known as a very excellent shelter for entomopathogenic fungi, since it protects them from ultraviolet radiation, and other adverse abiotic and biotic influences. However, Beauveria bassiana was the only entomopathogenic isolate. This is expected, since the Insect bait method was not used as mentioned earlier; soil samples were plated onto Potato Dextrose Agar. The Insect bait method is a better isolation technique, since it exploits the saprotrophic abilities of the pathogenic fungi [17]. Moreover, according to research conducted by [18], species of Aspergillus and Beauveria Bassiana were found to have high isolation rates from soil samples.

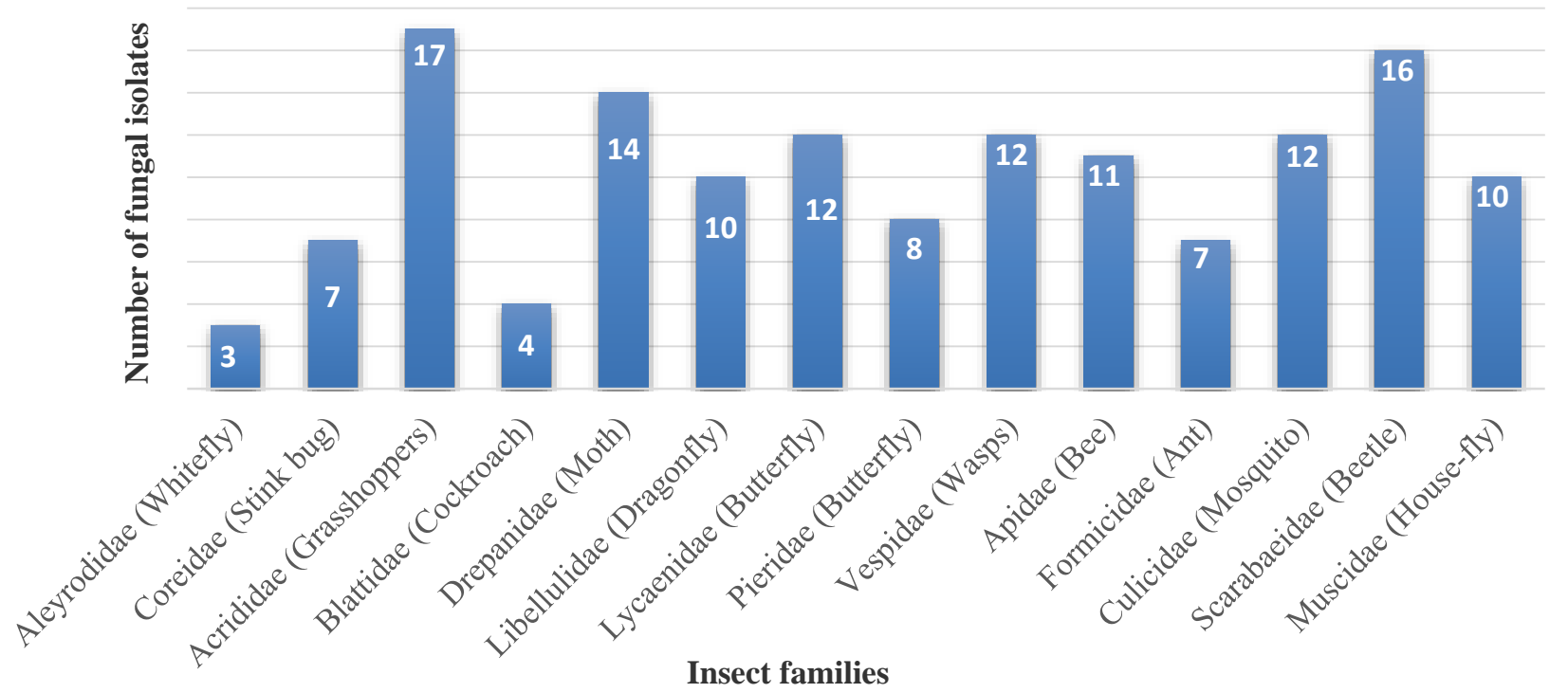

Figure 3 Diversity of fungal isolates on insect family

Out of the 14 insect families, Acrididae had the greatest diversity of fungal isolates; since it had the greatest number of species overall (figure 3). This was followed by Scarabaeidae and then Drepanidae. Lycaenidae, Vespidae and Culicidae had similar diversity. These were followed by Apidae, Libellulidae and Muscidae, Pieridae, Coreidae and Formicidae, Blattidae and finally, Aleyrodidae. Acrididae is expected to be the most diverse, since grasshoppers were 
found in every bio-system sampled. They are known to reside in fields, being exposed to various habitats; hence accounting for the great diversity of fungal isolates [20].

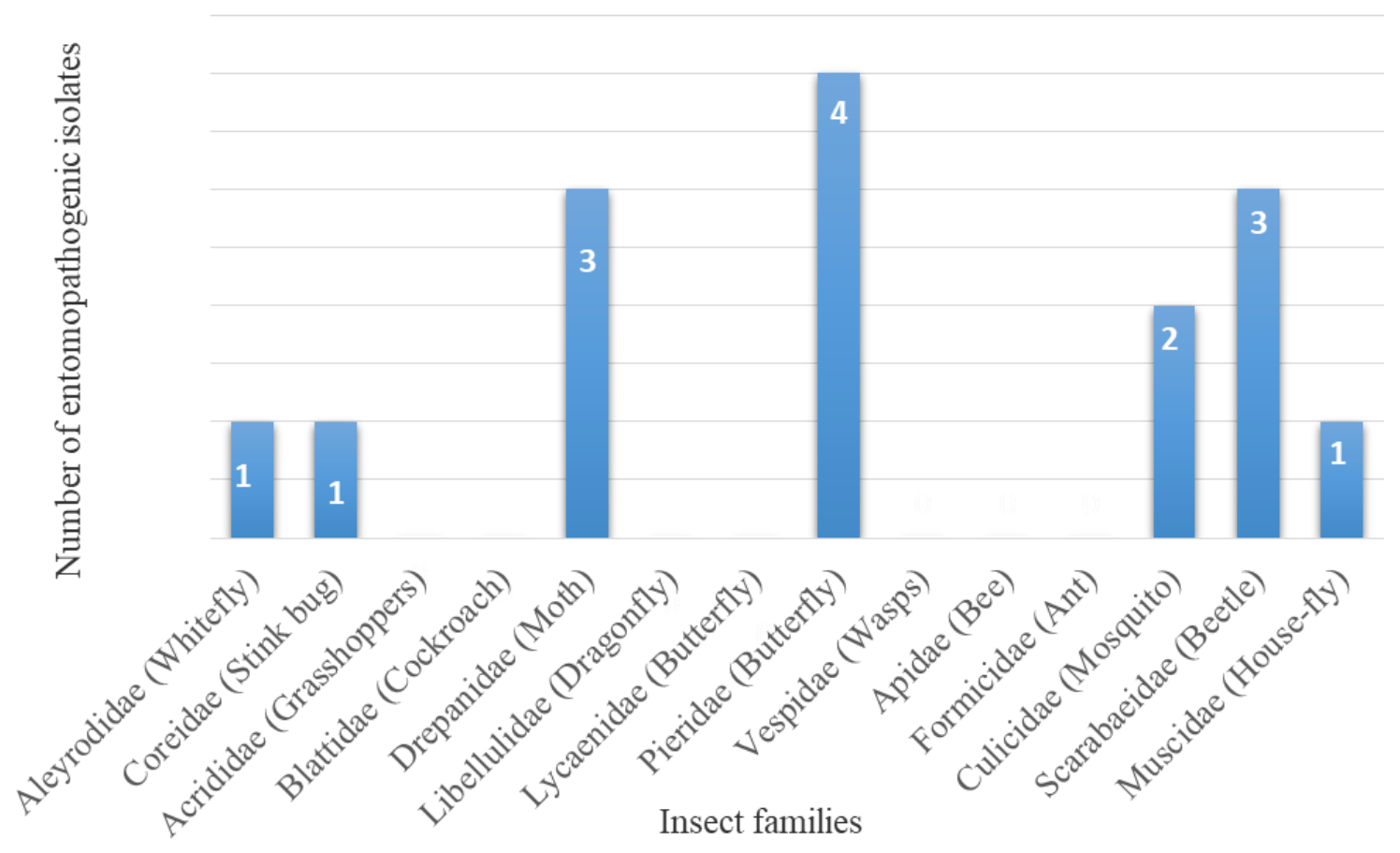

Figure 4 The diversity of insect families that possesses entomopathogenic fungi

Pieridae was found to possess the greatest diversity of entomopathogenic fungi. This family was then followed by Drepanidae and Scarabaeidae, Culicidae, and finally Aleyrodidae, Coreidae, and Muscidae (figure 4). No entomopathogenic fungi was obtained from families Acrididae, Blattidae, Libellulidae, Lycaenidae, Vespidae, Apidae and Formicidae.

Table 3 The entomopathogenic fungal isolates obtained from the soil samples

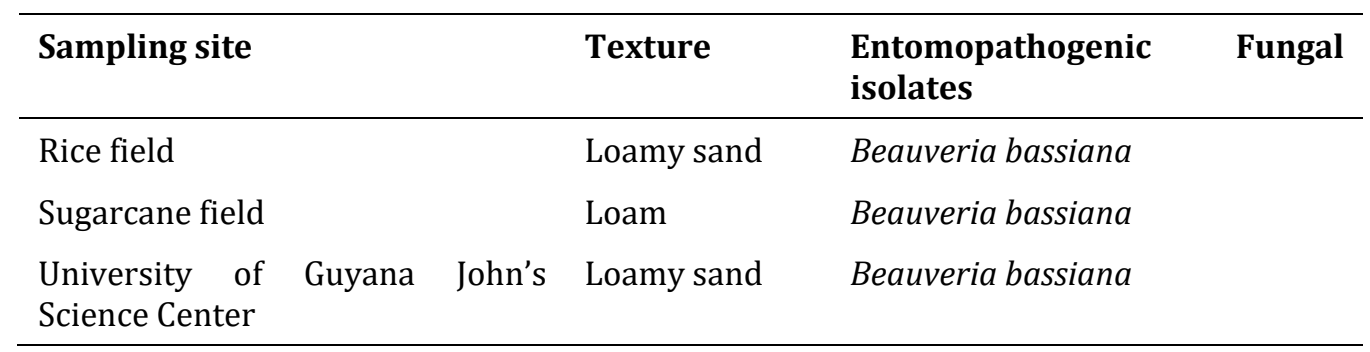

As mentioned before Beauveria bassiana was the only entomopathogenic fungi obtained from the soil samples (Table 3). Additionally, the soils obtained from each bio-system were similar in texture, ranging from loamy sand to loam. Moreover, $B$ bassiana was also found to be the most frequent entomopathogenic isolate found in the soils samples, in a research conducted by Asensio and co-workers in 2003.

The Rice field and Sugarcane field were agricultural areas with moderate vegetation, and very little anthropogenic activities. The University of Guyana John's Science Center had a lot of anthropogenic activities; however, there were numerous farming taking place around the Center (Table 4). 
Table 4 Parameters studied in the sampling areas

\begin{tabular}{|c|c|c|c|c|}
\hline Characteristics & Rice Field & $\begin{array}{l}\text { John's } \\
\text { University } \\
\text { Campus }\end{array}$ & $\begin{array}{l}\text { Science Center, } \\
\text { of Guyana, Berbice }\end{array}$ & $\begin{array}{l}\text { Sugarcane } \\
\text { field }\end{array}$ \\
\hline Vegetation & Moderate & Very little & & Moderate \\
\hline Pond/trench & Yes & Yes & & Yes \\
\hline $\begin{array}{l}\text { Anthropogenic } \\
\text { activities }\end{array}$ & Very little & A lot & & Very little \\
\hline $\begin{array}{l}\text { Cracks } \\
\text { crevices }\end{array}$ & Very little & A lot & & Very little \\
\hline Dustbins & No & Yes & & No \\
\hline Canteen & No & Yes & & No \\
\hline
\end{tabular}

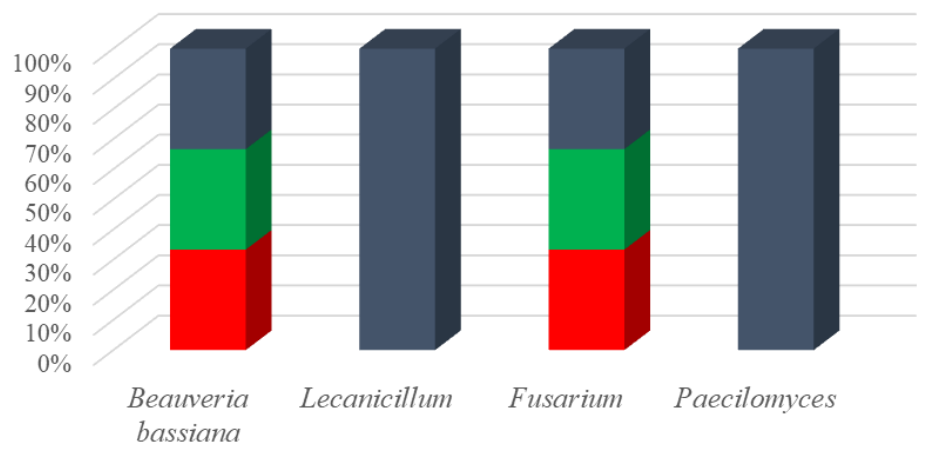

- Ricefield $\mathbf{n}$ University of Guyana John's Science Center $\mathbf{m}$ Sugarcane field

Figure 5 Entomopathogenic fungal diversity in different sampling area

As mentioned before, four entomopathogenic isolates were obtained (figure 5). Two species were isolated from both the rice field and University of Guyana John's Science Center as seen in the graph above. They were Beauveria bassiana and Fusarium. The sugarcane field was found to be more diverse; all entomopathogenic species obtained, was found there. As seen in the graph, these species were Beauveria bassiana, Lecanicillium, Fusarium and Paecilomyces. Additionally, B. Bassiana and Fusarium species were also found inhabiting agricultural areas, in a research conducted by [10].

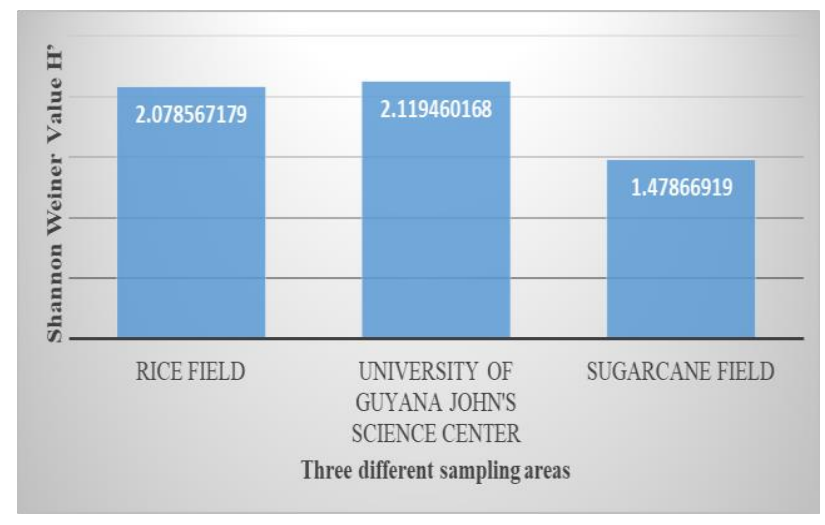

Figure 6 Diversity among three sampling areas are in terms of insects 
According to [21], Shannon Wiener Diversity Index is denoted by $\mathrm{H}^{\prime}$ and calculates the diversity of the community. It combines richness with how many individuals are in each taxon. According to the calculations done in excel, Shannon Wiener index is equal to 2.079 for the rice field, 2. 119 for the University of Guyana John's Science Center and 1.479 for the sugarcane field (See appendix E for formula used and tables 10,11 and 12 in appendix C for tables computed in excel). As seen in the graph above, The University of Guyana John's Science Centre was found to be the most diverse, followed by the rice field. The sugarcane field was the least diverse in terms of insects, even though it had the greatest diversity of entomopathogenic isolates. The diversity found at the University can be accounted for, due to the vast varies of vegetation growing and vast amount of pollinators.

Table 5 ANOVA table for the insect families and different sampling areas

\begin{tabular}{|c|c|c|c|c|}
\hline $\begin{array}{l}\text { Source } \\
\text { variable }\end{array}$ & $\mathbf{F}$ & p-value & F crit & Significance \\
\hline Insect Families & 0.698773 & 0.747443 & 2.119166 & Not significant \\
\hline $\begin{array}{l}\text { Different sampling } \\
\text { areas }\end{array}$ & 0.376014 & 0.690266 & 3.369016 & Not significant \\
\hline
\end{tabular}

From table 5 , it can be seen that the $p$-value is greater than $5 \%$ or $0.05 \%$ this means that the three bio-systems were not significantly different from each other; even though the University of Guyana John's Science Center was found to be the most diverse

\section{Conclusion}

It can be concluded that, Aleyrodidae, Coreidae, Acrididae, Blattidae, Drepanidae, Libellulidae, Lycaenidae, Pieridae, Vespidae, Apidae, Formicidae, Culicidae, Scarabaeidae, and Muscidae were the 14 insect families obtained. Acrididae was found to have the greatest diversity of fungal isolates, whilst Pieridae was the found to be more diverse with entomopathogenic fungi. Beauveria bassiana, Lecanicillium, Paecilomyces and Fusarium were the four entomopathogenic fungi obtained. Amongst them, only Beauveria bassiana was isolated from the soil samples, while all four were isolated from the insects. Additionally, the secondary colonizer obtained includes Alternaria, Curvularia, Penicillium and Cladosporium. While the non-pathogenic colonizer includes Aspergillus niger, Aspergillus flavus, Aspergillus versicolor, Aspergillus clavatus, Phytophthora, Pyricularia, Mucor, Bipolaris, Trichophyton, Trichoderma and Rhizopus. All bio-systems chosen had entomopathogenic isolates; however, the sugarcane field was found to be more diverse as compared to the other two. Lastly, since entomopathogenic fungi are present in the bio-systems chosen, further investigations are necessary to establish an effective biocontrol strategy.

\section{Compliance with ethical standards}

\section{Acknowledgments}

Authors very thanks full to the staff of the Biology Department at the John's Science Center. University of Guyana, Berbice Campus, Tain, Guyana, South America.

\section{Disclosure of conflict of interest}

The authors are pronounced that this manuscript do not have any conflict of interest.

\section{References}

[1] Chapman AD. (2009). Numbers of living species in Australia and the World.

[2] Bale SJ, Van Lenteren CJ, and Bigler F. (2007). Biological control and sustainable food production. Philosophical Transactions of the Royal Society B: Biological Sciences, 363(1492), 761-776.

[3] Pestano F, Gomathinayagam S, Liverpool E and Ansari A. (2017). Investigation of Entomopathogenic Fungi from Insects at University of Guyana Turkeyen Campus. Current Trends in Biomedical Engineering \& Biosciences, 5(2), 001-005. 
[4] Tuininga AR, Miller JL, Morath S, Daniels TJ, Falco RC, Marchese M, Sahabi S, Rosa D and Stafford KC. (2009). Isolation of Entomopathogenic Fungi from Soils and Ixodes scapularis (Acari: Ixodidae) Ticks: Prevalence and Methods. Journal of Medical Entomology, 46.

[5] Augustyniuk-Kram A and Kram JK. (2012). Entomopathogenic Fungi as an Important Natural Regulator of Insect Outbreaks in Forests (Review). Forest Ecosystems - More than Just Trees, Juan A. Blanco, Intech0pen, 12, 265-282.

[6] Moore J. (2001). An Introduction to the Invertebrates: Why are insects such successful land animals?

[7] Pluke R, Permaul D and Leibee G. (1999). Integrated Pest Management and the Use of Botanicals in Guyana. Scholtz, R. (2018). Guyana GDP and Economic Data. Global Finance.

[8] Natram I. (2017). Region two rice farmers battling paddy bugs. Guyana Times Inc.

[9] Scholtz R. (2018). Guyana GDP and Economic Data. Global Finance.

[10] Torres-Barragan A, Anaya LA, Alatorre R and Toriello C. (2004). Entomopathogenic fungi from 'El Eden' Ecological Reserve, Quintana Roo, Mexico. Mycopathologia, 158(1), 61-71.

[11] Shahid AA, Rao AQ, Bakhsh A and Husnain T. (2012). Entomopathogenic fungi as biological controllers: New insights into their Virulence and pathogenicity. Archives of Biological Sciences, 64 (1), 21-42.

[12] Black K. (2011). Business Statistics: For Contemporary Decision Making.

[13] Asensio L, Carbonell T, Lopez- Jimenez JAand Lopez- Llorca LV. (2003). Entomopathogenic fungi in soils from Alicante province. Spanish Journal of Agricultural Research.1.

[14] Dunn AG. (1996). Insects of the Great Lakes Region: Insect Classification and Identification. Great Lakes environment. Michigan: University of Michigan Press.

[15] Hayes Microbial Consulting. (2008). Fungal Library.

[16] Herreroa N, Duenasa E, Quesada-Moragab E and Zabalgogeazcoaa I. (2012). Prevalence and Diversity of Viruses in the Entomopathogenic Fungus Beauveria bassiana. Applied and Environmental Microbiology, 78, 8523-8530.

[17] Meyling VN. (2007). Methods for isolation of entomopathogenic fungi from the soil environment.

[18] Assaf HL, Haleem AR and Abdullah KS. (2011). Association of Entomopathogenic and Other Opportunistic Fungi with Insects in Dormant Locations. Jordan Journal of Biological Sciences, 4(2), 87-92.

[19] Animal corner. (2018). Grasshopper: Grasshopper habitat and grasshopper diet.

[20] Pielou C. (1975). Ecological Diversity. New York, NY: Wiley-Intescience Publication.

\section{How to cite this article}

Ferial P, Subramanian G, Abdullah A and Phillip D. (2019 Investigation of the occurrence of entomopathogenic fungi in soils and on insects from Corentyne Berbice, Guyana. GSC Biological and Pharmaceutical Sciences, 8(3), 01-09. 